\title{
STATUS KEPEMILIKAN LAHAN PENDUKUNG PERTUMBUHAN PERMUKIMAN KUMUH DI KAWASAN REL
}

\author{
Soraya Dwi Rachmawati ${ }^{1)}$ dan Anak Agung Sagung Alit Widyastuty ${ }^{2)}$ \\ ${ }^{1)}$ dan $^{2)}$ Program Studi Perencanaan Wilayah Dan Kota \\ Fakultas Teknik Sipil dan Perencanaan \\ Universitas PGRI Adi Buana Surabaya \\ Email: sorayadwirachmawati@yahoo.com
}

\begin{abstract}
Abstrak
Pesatnya perkembangan dan kepadatan penduduk di perkotaan menyebabkan ruang untuk permukiman menjadi sempit. Ruang permukiman yang sempit tidak mendukung sebagai tempat tinggal dan kegiatan perikehidupan dan penghidupan manusia. Kampung Lumumba Wonokromo Surabaya merupakan salah satu perkampungan kumuh yang berlokasi di tepi rel kereta api. Masyarakatnya hidup dengan keterbatasan fasilitas sarana dan prasarana serta tidak memiliki sertifikat tanah yang mengakibatkan aspek vitalitas non ekoniminya menjadi rendah. Tujuan penelitian ini adalah mengidentifikasi karakteristik permukiman kumuh kawasan rel kereta api berdasarkan aspek Vitalitas Non Ekonomi, Status Kepemilikan Tanah, Keadaan Prasarana dan Sarana, Prioritas Penanganan. Metode yang digunakan adalah deskriptif kualitatif. Pengumpulan data dilakukan dengan pengamatan langsung, kusioner, wawancara serta dokumentasi. Data yang diperoleh dianalisis dengan menggunakan teknik analisis pembobotan kriteria kawasan permukiman kumuh berdasarkan PU Cipta Karya tahun 2002. Hasil analisis menunjukkan permukiman kumuh di Kampung Lumumba lebih dominan di pengaruhi oleh kriteria status tanah. Kriteria status tanah memberikan nilai tinggi dibandingkan dengan kriteria yang lainnya yang mengakibatkan tingkat kekumuhannya tinggi. Prioritas penanganan yang dapat dilakukan terkait dengan status tanah ini, sebaiknya pemerintah melakukan penggusuran tempat tinggal mereka diganti dengan menyediakan lahan atau rumah susun yang layak untuk warga Lumumba.
\end{abstract}

Kata Kunci : Permukiman Kumuh, Status Kepemilikan Tanah, Vitalitas Non Ekonomi.

\begin{abstract}
The rapid development and population density in urban settlements cause space to be cramped. Narrow space settlements do not support as a residence and activities of human life and livelihood. Lumumba Wonokromo Kampung Surabaya is one of the slum is located at the edge of the railroad tracks. People live with limited infrastructure and facilities do not have land certificates which resulted in non Economic aspects vitality is low. The purpose of this study was to identify the characteristics of a slum area railroads based aspects of Non Economic Vitality, Land Tenure Status, State of Infrastructure, Priority Handling. The method used is descriptive qualitative. Data was collected through direct observation, questionnaire, interview and documentation. Data were analyzed using analysis techniques slum area weighting criteria based PU Cipta Karya 2002 analysis showed slum village dominant Lumumba more influenced by soil status criteria. Land status criteria provide high value in comparison with other criteria. Which resulted in a high level kekumuhannya. Priority handling may be related to the status of this land, the government should conduct their residence eviction replaced by providing land or flats for residents Lumumba decent.
\end{abstract}

Key words: Land Tenure Status, Non-Economic Vitality, Slum. 


\section{PENDAHULUAN}

Perkembangan perkotaan yang semakin pesat dan tingginya angka kepadatan penduduk merupakan permasalahan yang dihadapi perkotaan. Kota-kota besar di negara sedang berkembang seperti Indonesia memperlihatkan perbedaan perkembangan yang signifikan. Hal ini dapat terlihat dari perkembangan wilayah yang pesat sebagai simpul-simpul kegiatan yang erat dan seragam jika dibandingkan dengan perkembangan wilayah pedesaan. Sebagai konsekuensi perkembangan kegiatan yang pesat tersebut memberikan dampak negatif, yaitu meningkatnya arus urbanisasi ke kota-kota besar.

Pada tahun 2000 tingkat urbanisasi mencapai $40 \%$ dan diperkirakan akan menjadi 60\% pada tahun 2025 atau sekitar 160 juta orang. Sedangkan laju pertumbuhan penduduk perkotaan pada kurun waktu 1990-2000 tercatat setinggi $4,4 \%$ per tahun. Hal ini tidak sebanding dengan pertumbuhan penduduk keseluruhan yang hanya $1,6 \%$ per tahun. Fenomena urbanisasi yang terjadi di kota-kota besar tersebut mengakibatkan meningkatnya kebutuhan akan ruang kota, khususnya fasilitas perumahan dan permukiman sebagai salah satu kebutuhan dasar manusia. (Subekti, 2013). Permukiman adalah bagian dari lingkungan hidup di luar kawasan lindung, dapat berupa kawasan perkotaan dan perdesaan, berfungsi sebagai lingkungan tempat tinggal/hunian dan tempat kegiatan yang mendukung perikehidupan dan penghidupan. Permukiman dibagi menjadi 2 yakni permukiman kumuh dan permukiman tidak kumuh. Pada penilitian ini menjelaskan tentang permukiman kumuh. Kata "kumuh" menurut Kamus Besar Bahasa Indonesia diartikan sebagai kotor atau cemar. Jadi, bukan padat, rapat becek, bau, reyot, atau tidak teraturnya, tetapi justru kotornya yang menjadikan sesuatu dapat dikatakan kumuh.

Permukiman kumuh mengacu pada aspek lingkungan hunian atau komunitas. Permukiman kumuh dapat diartikan sebagai suatu lingkungan permukiman yang telah mengalami penurunan kualitas atau memburuk baik secara fisik, sosial ekonomi maupun sosial budaya, yang tidak mungkin dicapainya kehidupan yang layak bagi penghuninya, bahkan dapat pula dikatakan bahwa para penghuninya benarbenar dalam lingkungan yang sangat membahanyakan kehidupannya. Pada umumnya permukiman kumuh memiliki ciri-ciri tingkat kepadatan penduduk yang sangat tinggi, tidak memadainya kondisi sarana dan prasarana dasar, seperti halnya air bersih, jalan, drainase, sanitasi, listrik, fasilitas pendidikan, ruang terbuka/rekreasi, fasilitas pelayanan kesehatan dan perbelanjaan. Permukiman tepi rel adalah suatu bentuk permukiman di wilayah pinggiran kumuh yang khas di indonesia dengan ciri antara lain : penduduk mayoritas merupakan warga urban yang merantau ke daerah perkotaan yang tanpa memiliki identitas tetap, kondisi fisik bangunan yang semrawut dipinggiran rel yang kumuh tak terawat, kerapatan bangunan dan penduduk yang tinggi, termasuk kawasan kumuh perkotaan. (Subekti, 2013). Dari latar belakang di atas maka perlu adanya penelitian untuk mengidentifikasi permasalahan kepemilikan, sarana dan prasarana yang ada di permukiman kumuh pinggir rel kereta api Kampung Lumumba. Dengan mengidentifikasi permasalahan diharapkan mendapatkan rekomendasi yang akan digunakan oleh dinas pemerintah terkait dan juga masyarakat untuk menata permukimannya menjadi permukiman yang sehat, aman dan nyaman untuk dihuni. Tujuan penelitian ini adalah Untuk mengidentifikasi karakteristik permukiman kumuh kawasan rel kereta api di Kampung Lumumba Vitalitas Non Ekonomi, Status Kepemilikan Tanah, Keadaan Prasarana dan Sarana, Prioritas Penanganan. Serta untuk mengetahui arahan pengembangan permukiman kumuh di kawasan rel kereta api di Kampung Lumumba.

\section{METODE}

Rencana penelitian merupakan segala sesuatu yang mencakup tentang pendekatan yang digunakan di dalam penelitian. Penelitian deskriptif digunakan untuk membangun fenomena yang ada dengan memberi gambaran secara eksplisit. Sebagai contoh, penelitian ini dapat menguji gambaran keadaan strategi belajar tertentu dengan menggunakan uji hipotesis. Penelitian deskriptif dapat juga dipakai untuk mengukur frekuensi, contohnya, mengukur frekuensi munculnya bentuk sintaktik tertentu dalam ujaran bahasa kedua pabeberapa tahap pengembangan. Sangat penting ditekankan agar ketika jenis penelitian 
ini dimulai dengan sebuah pertanyaan atau hipotesis, maka fenomena yang digambarkannya tidak dapat dimanipulasi atau dipalsukan dalam hal apapun. Pada penelitian kali ini, saya menggunakan rancangan penelitian Deskriptif Kualitatif karena dirasa sesuai dengan masalah yang di angkat terutama masalah sarana dan prasarana yang ada di permukiman kumuh pinggir rel di kampung Lumumba. Dengan melakukan pengamatan, kusioner, wawancara serta dokumen. Rancangan penelitian Deskriptif Kualitatif dilakukan untuk menggambarkan vitalitas non ekonomi, variabel sarana dan prasarana, kepemilikan lahan dan permasalahan yang ada seputar ketidaksesuaian RTRW/RDTK, masalah sarana dan prasarana, masalaha kepemilikan lahan dan masalah kepadatan bangunan.

Metode pengumpulan data yang digunakan yaitu:

a. Survei Primer

Survei primer merupakan cara mengumpulkan data secara langsung. Survei primer bertujuan untuk memperkuat landasan berpikir setelah mengetahui pustaka agar dapat menyusun suatu perencanaan desa. Survei primer dapat dilakukan dengan menggunakan berbagai cara, yaitu:

1. Wawancara Teknik Wawancara, yatu melakukan tanya jawab kepada penduduk dan staf pemerintahan untuk memperoleh informasi atau data. Wawancara merupakan suatu proses interaksi dan komunikasi. Apapun bentuk wawancara yang digunakan, perlu disiapkan daftar pertanyaan dalam bentuk pedoman wawancara. Objek atau narasumber dalam wawancara tersebut ialah :
a. Ketua RT
b. Ketua RW atau Lurah
c. Masyarakat

2. Observasi Lapangan adalah metode pengumpulan data dimana peneliti mencatat informasi sebagaimana yang mereka saksikan selama penelitian.Penyaksian terhadap penelitian itu bisa berupa melihat, mendengar, merasakan kemudian dicatat seobjektif mungkin.

3. Kuesioner, yaitu suatu teknik dalam pengumpulan data dengan cara menggunakan daftar pertanyaan yang telah tersusun secara terstruktur kepada setiap responden terpilih. Penggunaan kuesioner ini bertujuan selain untuk memperoleh informasi yang relevan dengan tujuan survei juga untuk memperoleh informasi dengan realibilitas dan validitas setinggi mungkin (Singarimbun, 1995:175). Daftar pertanyaan yang akan diajukan kepada responden disusun dengan alternatif jawaban yang sekiranya sesuai dengan pendapat, pengetahuan dan pandangan dari responden.

4. Dokumentasi, yaitu tehnik pengumpulan data dengan cara mempelajari maupun mencatat arsiparsip atau dokumen, laporan kegiatan, monografi atau dafatr tabel statistik dan sebagainya yang berkaitan dengan topik penelitian untuk digunakan sebagai bahan menganalisa permasalahan.

b. Survei Sekunder Survei sekunder merupakan pengambilan data secara tidak langsung.

1. Studi Literatur Studi literatur yaitu metode pengumpulan data yang dilakukan dengan cara mempelajari buku panduan atau literatur-literatur, laporan, ataupun pustaka lain yang berhubungan dengan studi yang sedang dikaji agar memiliki dasar yang teoritis. Melalui studi literatur akan dilakukan studi komparatif antara fakta yang ada di lapangan dengan teori literatur.

2. Instansi Pengambilan data kepada instansi-instansi pemerintah yang terkait dengan penelitian, seperti Kantor Pemerintah Kabupaten Lamongan yang merupakan wilayah studi penelitian. Terkait dengan data : Monografi, dokumen permukiman dan data sertifikat tanah.

\section{Populasi dan Sampel}

Dalam penelitian ditentukan populasi dan sampel agar terlihat batas-batasnya secara jelas. Dalam pemilihan sampel penyebaran quisioner untuk masyarakat dilakukan dengan menggunakan teknik 'Quota samples', yaitu pemilihan sampel dengan menetapakan jumlah tertentu lalu meneliti subyek yang memenuhi 
persyratan ciri-ciri populasi (yang akan di bagikan quisioner dan yang akan di interview) dan mudah di temukan hingga terpenuhinya jumlah (quantum) yang telah di tetapkan (Suharsimi, 2006). Sasaran sampel adalah masyarakat Kelurahan Lumumba, dengan tujuan untuk mengetahui gambaran inspirasi mereka mengenai permukiman yang mereka inginkan. Karena jumlah penduduk Kelurahan Lumumba di ketahui sebesar \pm 690 jiwa, maka besarnya jumlah sampel sebesar 98 orang.

\section{HASIL DAN PEMBAHASAN}

Kampung Lumumba merupakan kampung yang berda di tepi Kereta Api. Dengan kepadatan penduduk yang tinggi. Daerah tersebut merupakan tanah milik PT. KAI dan Pemerintah Kota Surabaya. Warga yang menetap banyak yang berasal dari berbagai daerah mulai dari Madura, Surabaya, Madiun, Kediri dan masih banyak lagi yang selainnya. Mereka menetap di sana dengan alasaan sudah tidak ada tempat di Surabaya dan mahalnya harga tanah. Mereka hidup dengan menggunakan fasilitas yang seadanya. Banyak diantara mereka yang bekerja serabutan atau tidak menentu dengan penghasilan rata - rata di bawah UMR. Sehimgga mereka menjalani hidup di Kota Surabaya dengan serba seadanya dan terbatas agar dapat terus melanjutkan hidup.

\section{Luas Wilayah}

Kampung Lumumba memiliki Luas Wilayah sebesar $\pm 50.000 \mathrm{~m}^{2}$ dengan rincian panjang tanah $\pm 1 \mathrm{~km}$ dan lebar tanah $\pm 50 \mathrm{~m}$, yang terdiri dari 3 RT yakni : RT 1, RT 2 dan RT 3 Kampung Lumumba Kelurahan Nggelrejo. Dengan Batas Wilayah sebagai berikut :

a. Utara : berbatasan dengan tenjakan rel kereta api dan pom bensin Jagir b. Timur : berbatasan dengan Perumahan Penjernian dan Rel Kereta Api

c. Selatan : berbatasan dengan Jembatan dan Sungai Jagir

d. Barat : berbatasan dengan Jalan Raya Jagir dan PT. Jasa Tirta

\section{Fisik Bangunan}

Ada sebanyak $40 \%$ rumah yang permanen dan $60 \%$ rumah semi permanen. Dengan luas bangunan antara $24 \mathrm{~m}^{2}$ hingga 90 $\mathrm{m}^{2}$. Bangunan Rumah yang ada di Kampung Lumumba umumnya tidak memiliki halaman dan jarak antar bangunan sangat rapat sehingga tidak memiliki KDB (Koefisien Dasar Bangunan) dan KLB (Koefisien Lantai Bangunan) yang seharusnya. Di Kampung Lumumba tepatnya di RT 1 warganya banyak yang tidak memiliki kamar mandi pribadi. Sehingga menggunakan Ponten Umum / Kamar Mandi Kolektif yang di gunakan warga Kampung Lumumba dalam 1 gang. Sedangkan di RT 2 dan RT 3 sudah banyak warganya yang memiliki Kamar Mandi dalam.

\section{Kondisi Kependudukan}

Jumlah Kepala keluarga di
perkampungan Lumumba $\begin{array}{r}\text { sendiri ada } \\ \text { sebanyak } \pm 345 \text { KK. Dengan jumlah penduduk }\end{array}$
sebanyak \pm 1.380 jiwa. Sehingga tidak
terpungkiri jika setiap rumah diisi oleh dua
atau lebih dari dua kepala keluarga. Mayoritas
masyarakatnya beragama Islam. Setiap
tahunnya banyak yang keluar masuk untuk
menetap di tempat tersebut. Hal itu terjadi
karena kebanyakan bangunannya dijadikan
sebagai kos - kosan / rumah kontrakan
sehingga banyak pendatang dan banyak pula
yang pindah, akan tetapi jumlah pendatang
lebih besar dari jumlah warga yang pindah.

Tabel 1. Jumlah Penduduk yang Lahir, Mati, Datang dan Pindah

\begin{tabular}{lllllllll}
\hline \multicolumn{1}{c}{ RT } & KK & PNS & Swasta & $\begin{array}{c}\text { Wira } \\
\text { Swasta }\end{array}$ & Dagang & $\begin{array}{c}\text { Ibu Rumah } \\
\text { Tangga }\end{array}$ & $\begin{array}{c}\text { Belum } \\
\text { Bekerja }\end{array}$ & Jumlah \\
\hline 1 & 90 & - & 3 & 1 & 5 & 10 & 12 & 30 \\
2 & 100 & - & 1 & - & 9 & 15 & 7 & 32 \\
3 & 155 & 2 & 6 & 2 & 9 & 13 & 4 & 36 \\
Jumlah & $\mathbf{3 4 5}$ & $\mathbf{2}$ & $\mathbf{1 0}$ & $\mathbf{3}$ & $\mathbf{2 3}$ & $\mathbf{3 8}$ & $\mathbf{2 3}$ & $\mathbf{9 8}$ \\
\hline
\end{tabular}


Soraya Dwi Rachmawati \& Anak Agung Sagung Alit Widyastuty : Status Kepemilikan Lahan Pendukung Pertumbuhan Permukiman Kumuh di Kawasan Rel

Tabel 2. Banyaknya Jumlah Sampel Menurut Jenis Pekerjaan

\begin{tabular}{cccccc}
\hline RT & KK & Lahir & Mati & Datang & Pindah \\
\hline 1 & 90 & 3 & 1 & 15 & 10 \\
2 & 100 & 5 & 3 & 20 & 17 \\
3 & 155 & 9 & 3 & 25 & 20 \\
Jumlah & $\mathbf{3 4 5}$ & $\mathbf{1 7}$ & $\mathbf{7}$ & $\mathbf{6 0}$ & $\mathbf{4 7}$ \\
\hline
\end{tabular}

Dan perbandingan jumlah pendatang dengan masyarakat asli / menetap di sana dalam waktu lama jumlahnya hampir sama. Kebanyakan warga pendatang berasal dari daerah Jawa Timur, Madura dan Jawa Tengah. Sedangan untuk jumlah warga yang melahirkan lebih banyak dengan warga yang meninggal. Hal ini sama dengan jumlah pendatang yang lebih besar dari pada jumlah warga yang pindah.

\section{Jenis Pekerjaan}

Kebanyakan masyarakat Kampung Lumumba bekerja sebagai tukang becak, sopir bemo, pemulung, penjual gorengan dan masih banyak lagi yang selainnya. Dengan menggantungkan kehidupannya kepada profesi-profesi yang tersebut, mereka bertahan hidup di kota yang besar dan dengan penghasilan rata-rata mencapai $\mathrm{Rp}$. 500.000,sampai Rp. 2.000.000,-.

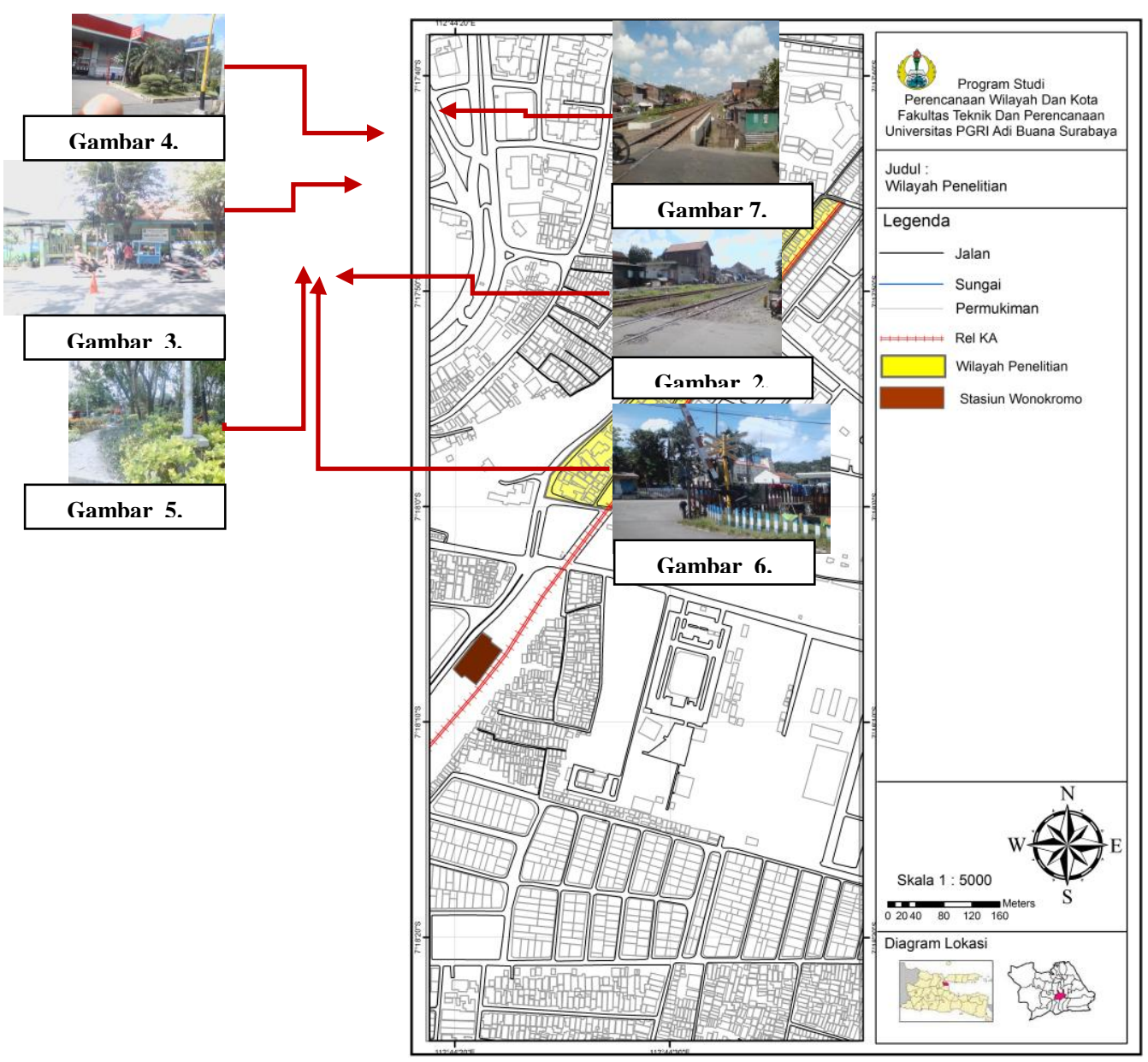

Gambar 1. Peta Wilayah Penelitian Permukiman Kumuh Pinggir Rel Kereta Api 

Pertumbuhan Permukiman Kumuh di Kawasan Rel

\section{Pendidikan}

Setiap tahun Kampung Lumumba selalu menjadi tempat tinggal bagi pendatang dari luar Surabaya yang ingin mengadu nasib di Surabaya dengan ijazah SD, SMP ataupun SMA sederajat namun tidak memiliki modal.
Kemauan yang kuat untuk merubah kondisi ekonomi mendorong mereka para warga Lumumba memanfaatkan peluang yang ada. Berikut merupakan tinggkat pendidikan warga Kampung Lumumba.

Tabel 3. Banyaknya Tingkat Pendidikan Warga di Kampung Lumumba

\begin{tabular}{cccccccc}
\hline RT & KK & SD & SMP & $\begin{array}{c}\text { SMA / } \\
\text { SMK }\end{array}$ & Diploma & Sarjana & Jumlah \\
\hline 1 & 90 & 5 & 15 & 10 & - & - & 30 \\
2 & 100 & 3 & 9 & 14 & 6 & & 32 \\
3 & 155 & 1 & 11 & 13 & 8 & 3 & 36 \\
Jumlah & $\mathbf{3 4 5}$ & $\mathbf{9}$ & $\mathbf{3 5}$ & $\mathbf{3 7}$ & $\mathbf{1 4}$ & $\mathbf{3}$ & $\mathbf{9 8}$ \\
\hline
\end{tabular}

\section{Status Kepemilikan Lahan}

Status Kepemilikan Tanah Kampung Lumumba di tepi Rel Kereta Api merupakan Tanah Milik PT. KAI sedangkan di sebelah barat yang berbatasan dengan Jalan Raya Jagir merupakan kawasan perumahan dinas milik
PDAM dan tanah milik Pemerintah Kota Surabaya. Sehingga para warga di Kampung Lumumba tidak ada yang memiliki Sertifikat Hak Milik Pribadi. Dan untuk luas bangunan tiap-tiap rumah warga di sana kebanyakan berukuran $24 \mathrm{~m}^{2}$.

Tabel 4. Jenis Kepemilikan Tanah di Kampung Lumumba

\begin{tabular}{ccccc}
\hline RT & KK & $\begin{array}{c}\text { Tanah } \\
\text { Pemkot }\end{array}$ & $\begin{array}{c}\text { Tanah PT } \\
\text { KAI }\end{array}$ & Jumlah \\
\hline 1 & 90 & 15 & 15 & 30 \\
2 & 100 & 16 & 16 & 32 \\
3 & 155 & 18 & 18 & 36 \\
Jumlah & $\mathbf{3 4 5}$ & $\mathbf{4 9}$ & $\mathbf{4 9}$ & $\mathbf{9 8}$ \\
\hline
\end{tabular}

Penggunaan lahan tersebut di manfaatkan warga sekitar untuk tempat tinggal dengan membayar uang sewa kepada PT. KAI untuk tanah di tepi rel kereta api, dengan harga yang bervariasi sesuai dengan luas rumah yang dimiliki dengan kisaran harga $\mathrm{Rp}$. 500.000 - Rp. 2.000.000 tiap tahunnya. Sedangkan untuk tanah milik Pemerintah Kota hanya dikenakan biaya pembayaran PBB.

\section{Sarana dan Prasarana}

Sebuah meteran air kolektif diperuntukkan lima rumah sekaligus. Memang ada rumah yang mempunyai kamar mandi dalam tapi masih banyak yang menggunakan fasilitas ponten umum sebagai sehari-hari karena tidak mempunyai kamar mandi dalam. Fasilitas pendidikan yang terdekat ada SD Ngagel, SMPN 12 Puskesmas berjumlah satu, rumahsakit ada beberapa, seperti RSI, Wiliambut, RS-AL dll. TPA terletak di depan hotel Novotel. Karena letak Sungai Jagir lebih dekat dengan TPA sehingga terkadang masih banyak pemandangan warga membuang sampah di Sungai Jagir. Kampung ini juga memiliki selokan lebarnya $\pm 15 \mathrm{~cm}$ dan kedalamannya $5 \mathrm{~cm}$ sehingga potensi banjir sangat mungkin terjadi. Tempat tinggal yang jauh dari kata nyaman harus diterima agar warga tetap bisa menjaga keberlangsungan hidupnya.

Taman yang ada di pinggir sungai jagir, yang letaknya bersebelahan dengan Kampung Lumumba. Taman tersebut sering menjadi tempat bermain oleh anak - anak warga Kampung Lumumba maupun sekitarnya. Di sebelah taman juga terdapat tempat penjual makanan atau warung - warung kecil. POM bensin yang ada di Jalan Wonokromo. Tanah ini merupakan tanah milik Pemerintah Kota Surabaya. Dengan Status Tanah Sertifikat Hak Sewa guna Bangunan.

Tempat Pembuangan Akhir yang berada di depan hotel Novotel dengan Jarak $\pm 500 \mathrm{~m}$. Karena letak Sungai Jagir lebih dekat dari pada TPA sehingga terkadang masih banyak 
Soraya Dwi Rachmawati \& Anak Agung Sagung Alit Widyastuty : Status Kepemilikan Lahan Pendukung Pertumbuhan Permukiman Kumuh di Kawasan Rel

pemandangan warga membuang sampah di Sungai Jagir. Terdapat Dinas Pekerjaan Umum Bina Marga dan Pematusan (Bidang Pematuan) yang berada di sekitar Kampung Lumumba. Tanah ini merupakan Tanah Milik Pemerintah Kota Surabaya.

\section{Aksesblitas}

Kampung Lumumba memiliki kelebihan dengan letak yang strategis yakni dekat dengan pusat perbelanjaan (DTC), dekat dengan stasiun Kereta Api Wonokromo dan dekat dengan pusat pemerintahan. Jarak Kampung Lumumba dengan Pusat Pemerintahan :

a. Jarak dari Pusat Pemerintahan Kecamatan $3 \mathrm{~km}$

b. Jarak dari Pusat Pemerintahan Kota 6 km

c. Jarak dari Pusat Pemerintahan Propinsi 8 $\mathrm{km}$

d. Jarak dari Ibu Kota Negara 900 km

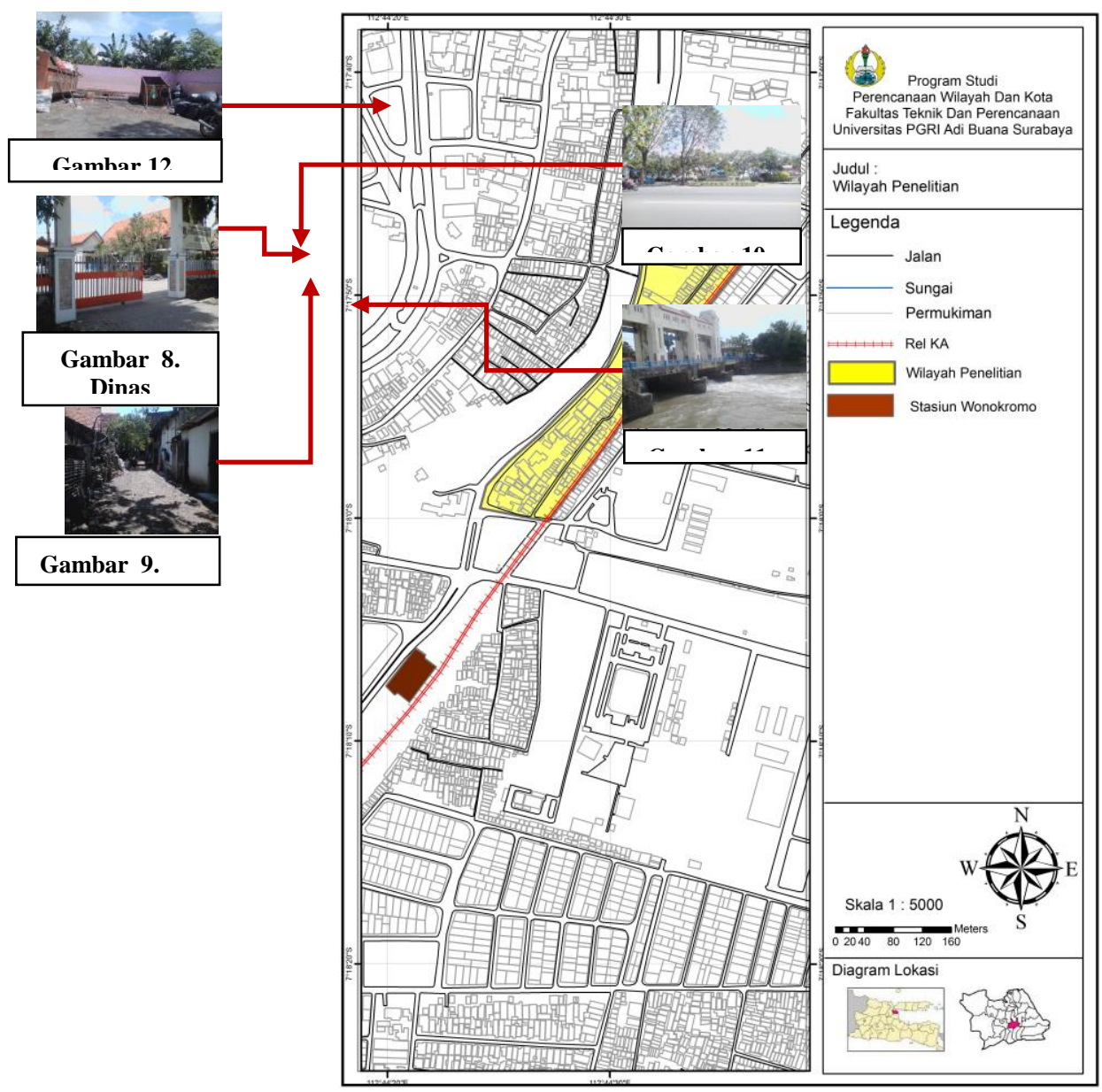

Gambar 2. Peta Wilayah Penelitian Permukiman Kumuh Pinggir Rel Kereta Api

\section{Penilaian Kriteria Vitalitas Non Ekonomi}

Dari perhitungan yang telah dilakukan diperoleh hasil Nilai Rentang (NR) dalam Kriteria Vitalitas Non Ekonomi sebesar 60. Kampung Lumumba berdasarkan Kriteria Vitalitas Non Ekonomi yakni meliputi : Kesesuaian dengan RTDRK, Kondisi Fisik Bangunan dan Kondisi Kependudukan diperoleh nilai sebesar 240. Hal ini jika di lihat berdasarkan Kategori yang telah di tentukan dalam Nilai Rentang, maka Keadaan Vitalias Non Ekonomi di kampung Lumumba berada dalam kategori tinggi. Yakni tingkat kesesuaian dengan RTDRK yang rendah (banyak yang tidak sesuai) karena dalam RTDRK lahan tersebut di gunkan untuk penambahan rel kereta api dan lahan terbuka hijau. Sedangkan untuk kondisi fisik bangunan banyak terdapat bangunan atau permukiman warga yang sangat padat hingga tidak ada jarak antara rumah satu dengan rumah yang selainnya. Dan pada tiap tahunnya tingkat penambahan bangunan liar sangat rendah, karena terbatasnya lahan yang tersedia. Dan 
untuk kondisi kependudukan di Kampung Lumumba berdasarkan jumlah penduduk di bandingkan luas lahan yang tersedia tidak sebanding, karena jumlah penduduk yang besar dengan lahan yang sempit menjadikan kawasan tersebut menjadi kawasan yang padat penduduk. Dengan tingkat pertumbuhan penduduk yang sangat tinggi, karena tiap tahunnya selalu ada pendatang untuk menetap di tempat tersebut. Hal ini terjadi karena banyaknya pendatang dari luar daerah untuk mengadu nasib di Kota Surabaya. Akan tetapi mereka terkendala dengan pendidikan yang rendah serta mahalnya harga tanah dan tidak tersediannya lahan yang layak untuk di tinggali. Sehingga mereka terpaksa menetap di sana karena harga sewa yang murah dan dekat dengan tempat mereka kerja.

\section{Penilaian Kriteria Status Tanah}

Dari perhitungan yang telah dilakukan diperoleh hasil Nilai Rentang (NR) dalam Kriteria Status Tanah sebesar 20. Kampung Lumumba berdasarkan Kriteria Status Tanah diperoleh nilai mutlak sebesar 100. Hal ini jika di lihat berdasarkan Kategori yang telah di tentukan dalam Nilai Rentang, maka keadaan Status Tanah di kampung Lumumba berada dalam kategori tinggi.

Yakni Status Kepemilikan Tanah Kampung Lumumba di tepi Rel Kereta Api merupakan Tanah Milik PT. KAI sedangkan di sebelah barat yang berbatasan dengan Jalan Raya Jagir merupakan kawasan perumahan Dinas milik PDAM dan tanah milik Pemerintah Kota Surabaya (Tanah milik negara). Sehingga para warga di Kampung Lumumba tidak ada yang memiliki Sertifikat Hak Milik Pribadi.

\section{Penilaian Kriteria Kondisi Prasarana Sarana}

Dari perhitungan yang telah dilakukan diperoleh hasil Nilai Rentang (NR) dalam Kriteria Vitalitas Non Ekonomi sebesar 50. Kampung Lumumba berdasarkan Kriteria Prasarana Sarana yakni meliputi : Kondisi jalan, drainase, air bersih, air limbah dan persampahan diperoleh nilai sebesar 160. Hal ini jika di lihat berdasarkan Kategori yang telah di tentukan dalam Nilai Rentang, maka Keadaan Prasarana Sarana di kampung Lumumba berada dalam kategori sedang.

Yakni Kondisi Jalan (bagian dalam) atau gang yang ada di kampung Lumumba sangat sempit sekitar $\pm 2 \mathrm{~m}$, sehingga hanya dapat dilalui 2 kendaraan roda 2. Akan tetapi jalan raya di sekitar Kampung Lumumba merupakan jalan yang banyak di lalui kendaraan karena letaknya yang strategis dengan pusat pemerintahan, perdagangan, kesehatan dan pendidikan. Sehingga daerah tersebut sering terjadi macet.

Pada gang Kampung Lumumba ada yang sudah di paving akan tetapi masih ada gang - gang kecil yang belum di paving, atau masih berupa tanah. Seharusnya gang - gang tersebut perlu di akan perbaikan jalan berupa pempavingan jalan agar terlihat rapi dan memenuhi standart yang telah di tentukan oleh RTDRK.Untuk kondisi Drainasenya, Kampung Lumumba memiliki selokan yang lebarnya $\pm 15 \mathrm{~cm}$ dan kedalamannya $5 \mathrm{~cm}$ sehingga potensi banjir sangat mungkin terjadi. Serta sebagaian besar berada di dalam rumah sehingga sulit untuk di bersihkan. Kebiasaan warga yang sering membuang sampah sembarangan mengakibatkan penyumbatan selikan. Sulit menggerakkan warga untuk melakukan kerja bakti dalam membersihkan saluran air karena letak saluran air berada di dalam rumah warga. Sehinggga, perlu adanya penambahan drainase, karena di kampung lumumba masih sedikit drainase yang ada dan sauran air (got) berada di dalam rumah warga. Hal ini akan mengakibakan sulitnya dalam perawatan. Karena sering terjadi penyumbatan yang dampaknya kembali di rasakan oleh warga sekitar. Sehingga perlu adanya penataan ulang dan penambahan drainase mengingat kepadatan penduduk dan bangunan yang ada. Serta menyadaran warga Kampung Lumumba untuk hidup bersih dengan tidak membuang sampah sembrangan terutama membuang sampah di drainase.

Untuk kondisi air bersihnya selama ini masih banyak yang menggunakan air sumur dan hanya beberapa yang menggunakan PDAM. Penggunaan PDAM pun dilakukan secara bersama atau menggunakan sistem kolektif (kelompok) bukan pribadi sehingga tidak semua rumah memilikinya. Maka dari itu diperlukan adanya penambahan Sumber Air Bersih melalui PDAM agar kebutuhan masyarakat akan Air Bersih dapat terpenuhi. Karena Air Bersih sangat diperlukan dalam kehidupan sehari - hari sehinggu penuh dilakukan langkah perioritas dalam penanganannya. PDAM dapat dilakukan 
secara kolektif mengingat masih banyak warga yang tidak memiliki kamar mandi dalam. Dan perlu adanya tandon atau tempat penampungan umum untuk memenuhi kebutuhan warga kampung Lumumba akan air bersih. Untuk sarana persampahan di Kampung Lumumba khususnya TPS (Tempat Pempuangan Sementara) berada di depan Hotel Novetel dengan jarak $\pm 500 \mathrm{~m}$ dari permukiman penduduk dan berada di daerah Penjernihan dengan jarak sekitar $\pm 1 \mathrm{~km}$ dari Kampung Lumumba. Karena letaknya dengan Tempat Pembuangan Sampah yang lumayan jauh mengakibatkan bnayak warga kampung Lumumba yang membuang sampah di sungai. Karena masih ada kebiasaan masyarakat dalam membuang sampah sembarangan dan profesi warga yang sebagai pemulung mengakibatkan keadaan Kampung Lumumba menjadi kurang nyaman. Sehingga perlu di liakukan pengambilan sampah secara rutin dan memberikan pengarahan kepada warga kampung lumumba akan pentingnya hidup bersih dengan membuang sampah pada tempatnya.

\section{Penilaian Kriteria Prioritas Penanganan}

Dari perhitungan yang telah dilakukan diperoleh hasil Nilai Rentang (NR) dalam Kriteria Status Tanah sebesar 90. Kampung Lumumba berdasarkan Kriteria prioritas penanganan diperoleh nilai mutlak sebesar 460. Hal ini jika di lihat berdasarkan Kategori yang telah di tentukan dalam Nilai Rentang, maka Keadaan Status Tanah di kampung Lumumba berada dalam kategori tinggi.

Dilihat dari letaknya kampung lumumba berada pada posisi yang strategis. Hal ini dapat diketahui dari jarak tempuh ke pusat pemerintahan yang cukup dekat. Dan berada pada kawasan metropolitan yang bergerak di bidang perdagangan dan jasa. Letaknya yang dekat dengan pusat pertumbuhan kota mengakibatkan kawasan tersebut menjadi kawasan yang banyak diminati oleh warga dalam maupun luar Surabaya.

\section{KESIMPULAN}

Dari ketiga aspek yang telah dibahas di atas didapat kesimpulan bahwasannya masalah utama permukiman kumuh di kampung lumumba berada pada kriteria status tanah. Yang merupakan tanah milik PT. KAI dan tanah milik pemerintah Kota Surabaya. Sehingga penanganan yang perlu dilakukan perlu adanya kerjasama antara pihak pemerintah dan warga sekitar. Langkah awal adalah dengan memberikan penyuluhan atau sosialisasi kepada warga kampung lumumba ke depan daerah tersebut akan menjadi lahan terbuka hijau dan penambahan jalur rel kereta api.

\section{Ucapan Terima Kasih}

Penelitian ini telah mendapatkan dukungan dari dinas Cipta Karya dan Tata Ruang atas data sekunder, Bapak Mulyono yang telah banyak membantu selama proses penelitian berlangsung.

\section{DAFTAR PUSTAKA}

Dinas Cipta Karya dan Tata Ruang. 2013. Rencana Detail Tata Ruang Kota (RTDRK) Unit Pengembangan Wonokromo, Surabaya.

Sadyohutomo, Mulyono. 2008. Manajemen Kota dan Wilayah-Realita dan Tantangan. Bumi Aksara, Bandung.

Setiani, Eko Putri. 2010. Permukiman Kumuh dan upaya untuk mengatasinya. http://repository.usu.ac.id (diunduh 15 November 2013)

Singarimbun, Masri. 1995. Metode penelitian survai. Jakarta: Pusaka LP3ES

Subekti. 2013. Menengok Permukiman Pinggiran Rel di Wonokromo Surabaya. http://ww.damandiri.or.id (diunduh 15 November 2013)

Soemarno, Ispurwono. 2008. Perumahan dan Penataan Lingkungan. BAPERTARUM-PNS. Surabaya. 